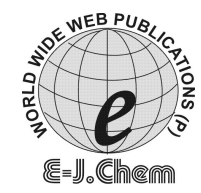

http://www.e-journals.net

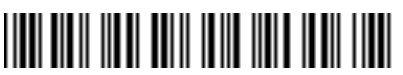

ISSN: 0973-4945; CODEN ECJHAO

E-Journal of Chemistry

Vol. 4, No. 4, pp. 474-479, October 2007

\title{
Isolation of Triterpenoid Glycoside from Bark of Terminalia arjuna using Chromatographic Technique and Investigation of Pharmacological Behavior upon Muscle Tissues
}

\author{
TANUSHREE PATNAIK, R K DEY* and PANCHANAN GOUDA \\ Department of Chemistry, S.K.C.G (Autonomous) College, \\ Paralakhemundi-761200, Orissa, India. \\ *Department of Applied Chemistry, Birla Institute of Technology, \\ Ranchi-835 215, India. \\ rkdey@rediffmail.com,pngauda@rediffmail.com
}

Received 21 January 2007; Accepted 2 March 2007

\begin{abstract}
This study reports the isolation and characterization of a new triterpenoid glycoside extracted from the bark of Terminalia arjuna. The isolation of the organic compounds was done using simple chromatographic technique. Compound characterization using various spectroscopic technique

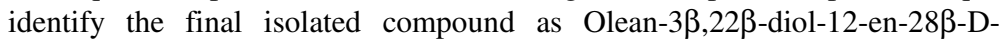
glucopyranoside-oic acid. The method of isolation is simple, cost effective and efficient. The preliminary bioactivity of the compound was also evaluated.
\end{abstract}

Keywords: Terminalia arjuna, Biochemical activity, Terpenoid, Extraction

\section{Introduction}

Terminalia arjuna Linn (fam: Combretaceae) is a large tree distributed throughout India. It is a commonly occurring medicinal plant growing as a $20-30 \mathrm{~m}$ high tree. It is also well recognized in Ayurveda for its various therapeutic values ${ }^{1,2}$. Chemical constituents of different classes such as hydrolysable tannins ${ }^{3}$, triterpenoid acids and their glycosides ${ }^{4,5}$, flavonoids ${ }^{6}$, Phenolics $^{7}$, phytosterol ${ }^{8}$, were reported from stem bark portion of Terminalia arjuna species. Additionally, Arjunglucoside I-III, aujunic acid, arjunetin, arjunolic acid, and terminoic acid also form group of important constituents of the bark ${ }^{9}$. A number of previously published papers reports the therapeutic properties for Terminalia arjuna ${ }^{10-13}$. 
The bark of T. Arjuna is used in India as cardioprotective agent in hypertension and ischaemic heart diseases ${ }^{14}$. It is rich in various chemicals such as polyphenols (about 60$70 \%$ ), phenyl propanoids, tannins (20-24\%), flavones, and flavonols and thus it finds useful applications in the treatment of diseases like ulcers, blood diseases, anemia and asthma. It also finds potential applications in curing hepatic, congenital, venereal and viral diseases. The bark powder is reported to show hypocholesterolaemic and antioxidant effect ${ }^{15}$. Various pharmacological studies deciphered usefulness of bark against angina pectoris, congestive heart failure, artheriosclerosis and myocardial necrosis. Besides, the medicinal use of bark as fungicidal, antimicrobial, antibacterial, antifertility and anti-human immune deficiency virus induced diseases has also been evaluated ${ }^{16-19}$. A number of terpenoid saponins (arjunic acid, arjunolic acid, arjunetin, arjunglycosides), flavonoids (arjunone, arjunolone, luteolin), gallic acid, ellagic acid and phytosterol have been isolated from the bark ${ }^{20-23}$.

The plant species used in the present investigation was collected from hilly areas situated in tribal belt of Parlakhemundi, a small locality of Ganjam and Gajapati districts of Orissa, India. The hilly areas of Ganjam-Gajapati districts form a part of the Eastern Ghats in India and they are floristically quite interesting for its connection to Himalayan region. Many valuable medicinal plants are available in this region and tribal healers used them as a low cost alternative to modern therapeutics. For example, the bark paste of Terminalia arjuna plant is being successfully used for the treatment of fractured bone of animals as well as human being of village area. It is believed that the fracture bones can be regenerated in a faster rate if the bark paste is used and plastered with the bark itself. In practice, the decoction of the bark is used therapeutically to relieve the pain and inflammation. In this context, the isolation and evaluation of organic compounds present in the plant species that are responsible for observed therapeutic effects is worth studied.

The present investigation reports the isolation of a triterpenoid glycoside from the bark of Terminalia arjuna species collected from the Parlakhemundi tribal area. The communication also reports the preliminary bioactivity studies carried out on muscle tissue of frog using standard methods to ascertain if the isolated compound has some contribution towards any pharmacological effect so that scientifically it could be related to the observed therapeutic properties for regeneration of bone and muscle tissue. Such a study may also be helpful to find some new potential applications of bark material. The method of isolation reported here is simple, cost effective and efficient, although isolation of glycoside type of compounds from the Terminalia arjuna speices had also been previously reported by researchers ${ }^{24}$.

\section{Experimental}

\section{Instrumentation and techniques}

Elemental analysis was carried out in a Perkin-Elmer elemental analyzer. Infrared spectra of the compounds were recorded in a JASCO Infrared spectrophotometer using $\mathrm{KBr}$ pallet. FTNMR spectra were recorded using DMSOd $6 / \mathrm{CDCl}_{3}$ as solvent and TMS as internal standard. EI-MS was recorded in a VG analytical 7070E instrument equipped with VG 11-250 data acquisition system.

Thin layer chromatography (TLC) was carried out using silica gel G (Ranbaxy). Measured thickness of the chromatographic plate coated with silica gel was $0.2 \mathrm{~mm}$. All chromatograms were developed in a glass chamber $\left(20 \mathrm{X} 10 \mathrm{~cm}^{2}\right)$ at room temperature of $23 \pm 2{ }^{\circ} \mathrm{C}$, and a relative humidity of approximately $40 \%$. Among different solvent systems tested by co-TLC method, benzene: ethyl acetate $(9: 1, \mathrm{v} / \mathrm{v})$ was found to be suitable for good separation and, therefore, this solvent system was chosen for preparative TLC. 


\section{Plant Material}

The fresh bark of $T$. arjuna was collected locally, authenticated by Taxonomist of Department of Botany, SKCG (Autonomous) College, Orissa, and the voucher specimen was deposited in the Herbarium of SKCG (Autonomous) College (Ref. No. 01/ 06).

\section{Extraction and isolation of compound}

The sun-dried stem bark was crushed into fine powder. Pulverized bark part $2.5 \mathrm{~kg}$ was exhaustively extracted with ethanol $(95 \%)$ at room temperature, $23 \pm 2{ }^{\circ} \mathrm{C}$, for 10 days. The ethanolic extract was filtered, distilled and concentrated to obtain the solid brownish residue (M.P $=158{ }^{\circ} \mathrm{C}$ ). The yield was $7.1 \% \mathrm{w} / \mathrm{w}$. The final weight was noted and stored.

The residue was treated with water. The water soluble and insoluble portions were separately collected by filtration (G4 crucibles). Initial study in preparative TLC of the water-soluble part does not give any spot in the chromatogram and, therefore, we did not take any further attempt to analyze the water-soluble part.

The water insoluble alcohol extract was found to be partially soluble in different organic solvents like ethyl acetate, benzene, chloroform, carbon tetrachloride and methyl alcohol. So, it was dissolved in ethyl alcohol and allowed to stand for nearly $4 \mathrm{~h}$ then filtered and separated into ethyl alcohol soluble (A) and insoluble (B) parts.

The ethyl alcohol soluble (A) portion was treated with equal volume of distilled water and ethanol mixture (1:1) and then treated with ethyl acetate in separating funnel, which separated into organic layer and the aqueous layers. The process was repeated for at least three times to ensure complete extraction.

From the organic layer taken separately, the ethyl acetate was distilled out by and it was further treated with dry petroleum benzene and the purity of the compound was tested using thin layer chromatographic system developed in a benzene and ethyl acetate (9:1) solvent system. Three different spots were obtained when the chromatogram was placed inside an Iodine chamber, indicating the presence of three different compounds. All the three compounds were separated and collected using preparative thin layer chromatography. However, we failed to get a quantitative yield of the materials and therefore, further analysis of the compounds was not undertaken in the present investigation.

The aqueous layer obtained in the above process was treated with distilled water and filtered. In this case, the thin layer chromatography developed in benzene and ethyl acetate (9:1) solvent system does not yield any spot thus confirming absence of any compounds.

The residue portion (B) was refluxed with petroleum benzene for $12 \mathrm{~h}$ using reflux condenser and water bath. It was filtered and separated into two parts, residue (C) and filtrate (D). The filtrate (D) was subjected to preparative TLC and no spot was found, thus confirming absence of any compound. The residue (C) was again refluxed with dry benzene for $12 \mathrm{~h}$ and filtered. No residue was obtained in this case. So, the benzene soluble portion was concentrated using a hot water bath to obtain a greenish-white colored residue. This was further treated with petroleum benzene mixture $(9: 1)$ and recrystallized in benzene to give a white color compound (D), (M.P. $=160-162{ }^{\circ} \mathrm{C}$ ), with quantitative yield.

\section{Action of extract (D) on frog muscle tissue}

5 frogs of both sex, weighing between 175 to $190 \mathrm{~g}$ were chosen. The animals were kept in an aquarium and brought to the laboratory during experiment. All animals were handled according to the International Guiding Principles for Biomedical Research Involving 
Animals (C.I.O.M.S, 1985). Rectus abdomius muscle of the frog was dissected out humanly and divided longitudinally. The muscle was fixed in an isolated organ bath. The action of the extract (D) on smooth muscle was employed using various dosages of acetylcholine $(0.1,0.3$ and $0.5 \mathrm{~mL})$, acetylcholine-extract combination $(0.1,0.3$ and $0.5 \mathrm{~mL})$, and acetylcholinepanchronium bromide combination $(0.1,0.3$, and $0.5 \mathrm{~mL})$. Panchronium bromide is a standard neuromuscular blocking agent is used as control.

\section{Results and Discussion}

\section{Characterization of compound D}

The product $\mathrm{D}$ is a white crystalline solid $(12 \mathrm{mg})$, with melting point $160-162{ }^{\circ} \mathrm{C}$. The elemental analysis of the compound shows experimental value of $\% \mathrm{C}: 67.8, \% \mathrm{H}: 9.0$, corresponding to calculated value as $\% \mathrm{C}: 68.1$ and $\% \mathrm{H}: 9.1$. The UV $(\lambda \max )(\mathrm{MeOH})$, is found at $219.5 \mathrm{~nm}$, assigned to the presence of alkyl constituent of a carbocyclic ring.

The IR (KBr pallet) shows a strong absorption band at $3398 \mathrm{~cm}^{-1}$ assigned to the presence of hydroxyl groups in the compound. Apart from this, presence of other vibration frequencies at 2938 and $1691 \mathrm{~cm}^{-1}$ were assigned to presence of saturated $\mathrm{C}-\mathrm{H}_{\text {str }}$, and carboxyl group, respectively. The peak noticed at $1051 \mathrm{~cm}^{-1}$ was assigned to the presence of glycosidic linkage in the molecule.

The ${ }^{1} \mathrm{H}$ - NMR (300 MHz, $\mathrm{CDCl}_{3}$ ) gave the signals at $\delta_{\mathrm{ppm}} 0.68,0.87,0.94,0.98$ and 1.0 (each singlet), assigned to $21-\mathrm{H}, 7 \mathrm{x}-\mathrm{CH}_{3}$. The assignments of the various signals are: $\delta_{\mathrm{ppm}} 2.9(\mathrm{~d}, 1 \mathrm{H}), 3.1-3.7$ (bm, $6 \mathrm{H}$, glucosidic ring protons), 3.9 (bm, H-1, C-3 proton), 5.2 (d, $1 \mathrm{H}$-anomeric proton) and $7.6(\mathrm{~s}, 1 \mathrm{H}, \mathrm{C}-12$ proton).

${ }^{13} \mathrm{C}$-NMR $\left(300 \mathrm{MHz}\right.$, DMSO d 6 ) shows peak at $\delta_{\mathrm{ppm}} 179.3$ correspond to C-28, 142.4 correspond to $\mathrm{C}-13$, and 122.6 correspond to presence of double bond at $\mathrm{C}-12$. In addition, the C-3 and C-22 gave signals at $\delta_{\mathrm{ppm}} 82.3$ and 80.1 respectively. The peaks at $\delta_{\mathrm{ppm}} 77.4$, $67.2,77.0,67.0,76.6$ and 66.5 correspond to presence of sugar unit carbon atoms.

The EI-MS spectroscopy of the present compound exhibited a pseudo molecular ion peak at m/z 634 and fragmented peaks at m/z 472, 249, 231, 219, 186, 158, 100 and 70.

Based on the above characterization and by comparing with other similar compounds, the proposed structure of the new isolated compound is given in Figure 1.

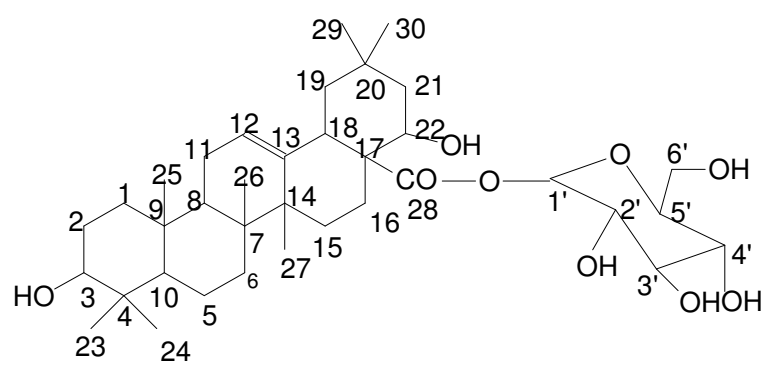

Figure 1. Olean-3 $\beta$, 22 $\beta$-diol-12-en-28 $\beta$-D-glucopyranoside-oic acid.

\section{Application of the compound D on frog muscle tissue}

Graphical results from the kymograph recordings of the responses in contractile activity of rectus abdominus muscle tissue of the frogs treated with various dosages of acetylcholine and the extract is shown in Figure 2. It was observed that the extract reduced the contractile 
response of acetylcholine. Panchronium combines with the cholinoceptive sites and blocks the transmitter action of the acetylcholine ${ }^{25}$, therefore, mechanism of the action of the extract may be due to the action on the muscarinic receptors, thereby blocking the transmitter action of acetylcholine.

From the proposed structural viewpoint, one of the functional $\mathrm{OH}$ group is in close proximity and in chelating position to the carboxylate linkage. So a linkage is more probable at the same position, which may be responsible for the above pharmacological activity. Apart from this, the presence of other functional $\mathrm{OH}$ groups in suitable position in the ring may also contribute to the pharmacological activities in various compounds. So in this case, the combination might be factored in observed pharmacological activity of the compound.

From the above studies it may be inferred that the isolated compound (D) could be a contributing factor leading to healing of growth of muscle tissue and healing of wounds as shown in practice. In a plant species the pharmacological activities of the overall extract is difficult to correlate to a specific compound because the effect may be due to presence of many other active chemicals like terpenes, alcohols, aldehydes and esters and, therefore, this complexity and variability may also contribute to the overall pharmacological activities ${ }^{26}$.

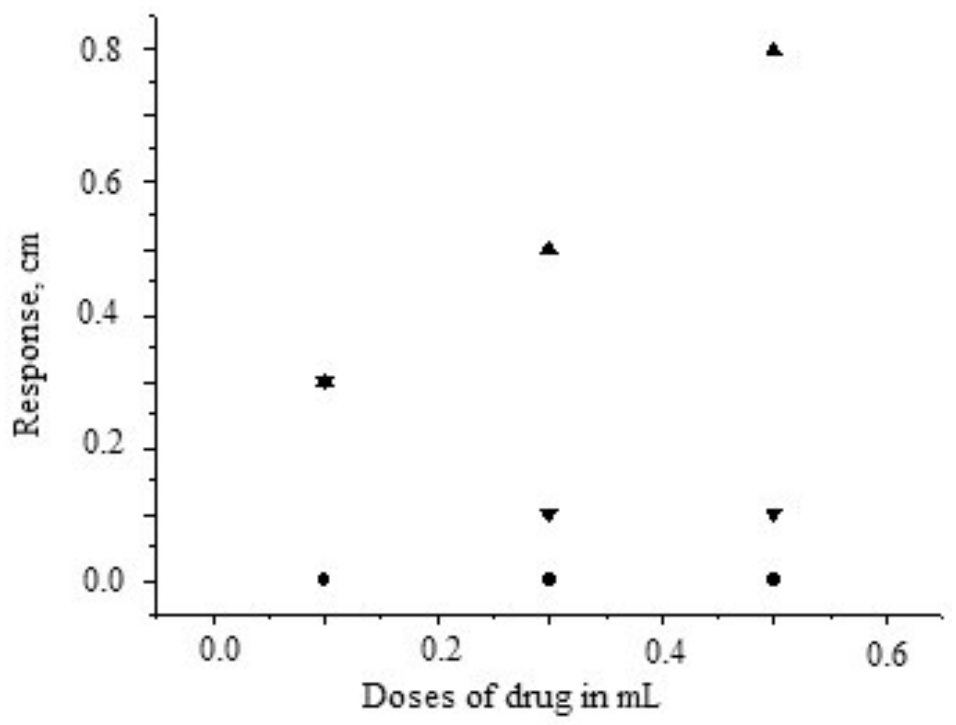

Figure 2. Responses of rectus abdominus muscle of frogs to acetylcholine $(\boldsymbol{\Delta})$, acetylcholine-plant $\operatorname{extract}(\boldsymbol{\nabla})$, acetylcholine-pancronium bromide $(\bullet)$.

\section{Conclusions}

The study highlights the extraction of a triterpenoid compound from the bark of Terminalia arjuna and its application upon the frog muscle tissue to ascertain its bioactivity. Preliminary findings towards such kind of application were encouraging and some more studies are in progress to establish optimized conditions to examine in detail various effects toward the growth of muscle tissues. This will be helpful in scientifically correlating the practical observation made by traditional healer regarding its successful application on wounds and broken bones. In addition to it, the proposed extraction and quantification 
method of isolation of organic compound is a simple and efficient method, which may be helpful in subsequent future studies in this direction.

\section{Acknowledgements}

The authors acknowledge CDRI, Lucknow for providing spectra of the samples. Kind help and suggestions of faculties of Department of Pharmacology, BIT, Mesra in carrying out the pharmacological study is thankfully acknowledged. PG is thankful to Government of Orissa for financial support to carry out the research work.

\section{References}

1. Kalola J and Rajani M, Chromatographia, 2001, 63, 475.

2. Nadkarni K M, The Indian Materia Medica, Popular Prakashan, India, 2000, 1, 1198 - 1202.

3. Kandil F E and Nassar M Y, Phytochem., 1998, 47, 1567.

4. Tripathi V K, Pandey V B, Udupa K N and Rucker G, Phytochem., 1992, 31, 349.

5. Ahmad M U, Mullah K B, Nörin and Ulla T J K, Ind. J. Chem., 1983, 22B, 738.

6. Sharma P N, Shoeb A, Kapil R S and Popli S P, Ind. J. Chem., 1982, 21B, 263.

7. Anjaneyulu A S R and Prasad A V R, Phytochem., 1982, 21, 2057.

8. Row L R, Murty P S, Subba Rao G S R, Sastry C S P and Rao K V J, Ind. J. Chem., $1970,8,716$.

9. Murae T, Tsuyuki T, Takahashi, and Sawani M, Bull. Chem. Soc. Jpn., 1976, 49, 3213.

10. Dwivedi S and Udupa N, Fitoterapia, 1989, 60, 413.

11. Anjaneyulu A S R and Prasad A V R, Ind. J. Chem., 1982, 21B, 530.

12. Bharani A, Ganguly A and Bhargava K D, Int. J. Cardiol., 1995, 49, 191.

13. Shaila H P, Udupa S L, Udupa A L, Int. J. Cardiol., 1998, 67, 119.

14. Pawar R S and Bhutani K K, Phytomedicine, 2005, 12, 391.

15. Gupta R, Singhal S, Goyle A and Sharma V N, J. Asso. Physician, India, 2001, 49, 231.

16. Kumar R and Verma R K, Ind. Phytopathol., 1987, 40, 274.

17. Ray P G and Majumdar S K, Econ. Bot.,1976, 30, 317.

18. Shukla Y N, Srivastava A, Santha Kumar T R, Khanuja S P S and Kumar S, Ind. Drugs, 2000, 37, 60.

19. Seshadri C, Pillai S R Venkataraghawan. J. Sci. Res. Plants Med., 1981, $2,1$.

20. Miller A L, Alt. Med. Rev., 1998, 3, 422.

21. Kuscemoto I T, Nakabayashi T, Kida H, Miyashiro H, Hattori M, Namba T and Shimotohno K, Phytother. Res., 1995, 9, 180.

22. Jain V, Poonia A, Agrawal R P, Panwar R B, Kocher D K and Misra S N, Ind. Med. Gazette, 1992, 36, 56.

23. Chopra R N, Nayar S L and Chopra I C, Glossary of Indian Medicinal plants, New Delhi: C.S.I.R publication, 1956. p. 241.

24. Singh D V, Gupta M M, Tripathy A K, Prajapati V and Kumar S. Phytother. Res., 2004, 18, 131.

25. Sandabe U K, Onyeyili P A and Chibuzo G A, J Ethanopharmacol.,2006, 104, 283.

26. Belletti N, Ndagihimana M, Sisto C, Guerzoni M E, Lanciotti R and Gardini F, Agri Food Chem., 2004, 52, 6932. 


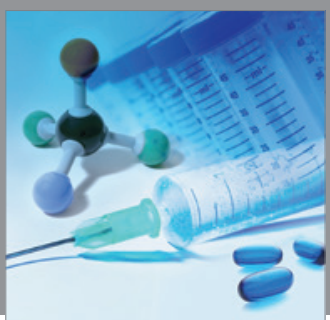

International Journal of

Medicinal Chemistry

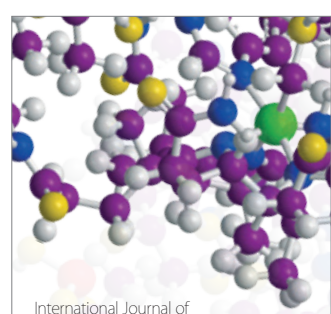

Carbohydrate Chemistry

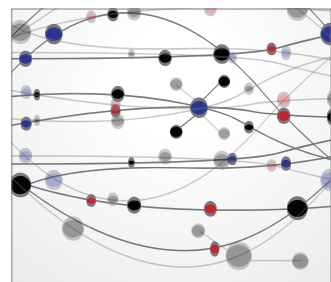

The Scientific World Journal
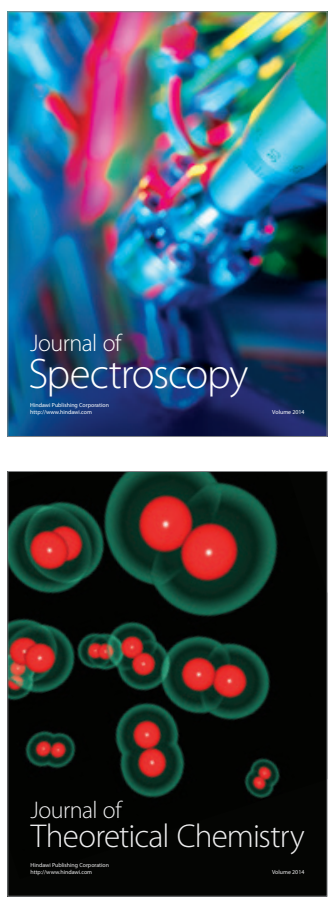
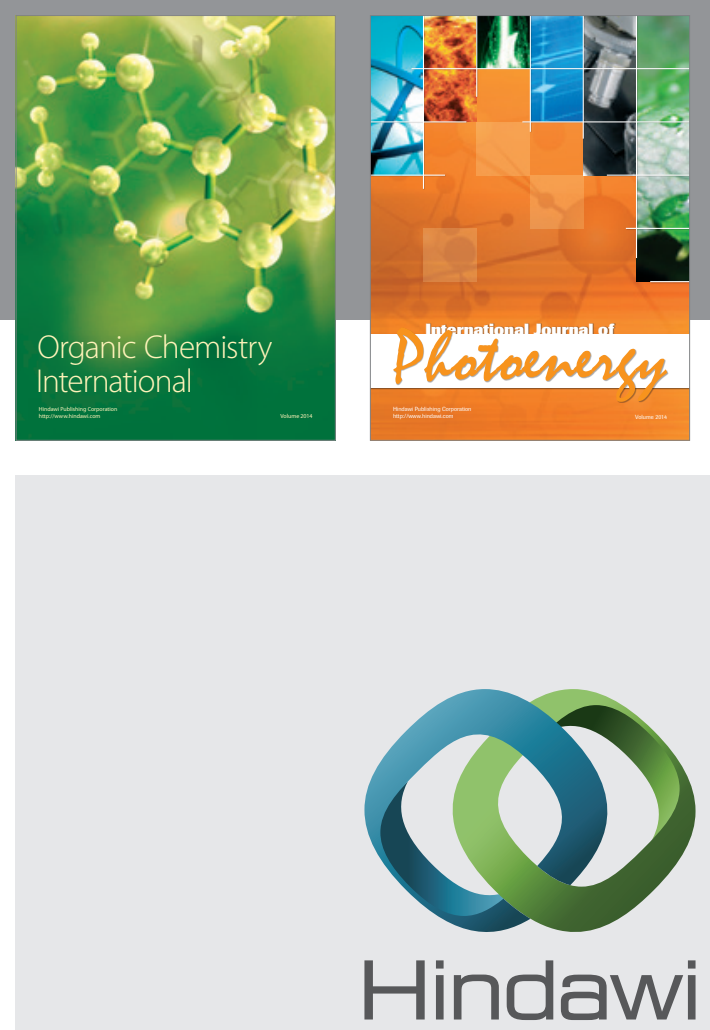

Submit your manuscripts at

http://www.hindawi.com
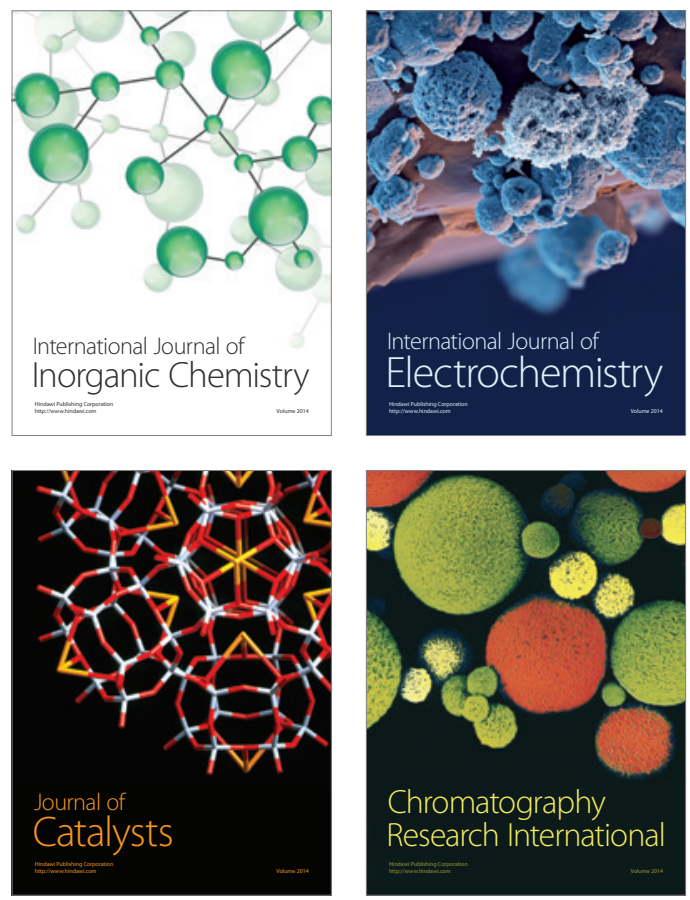
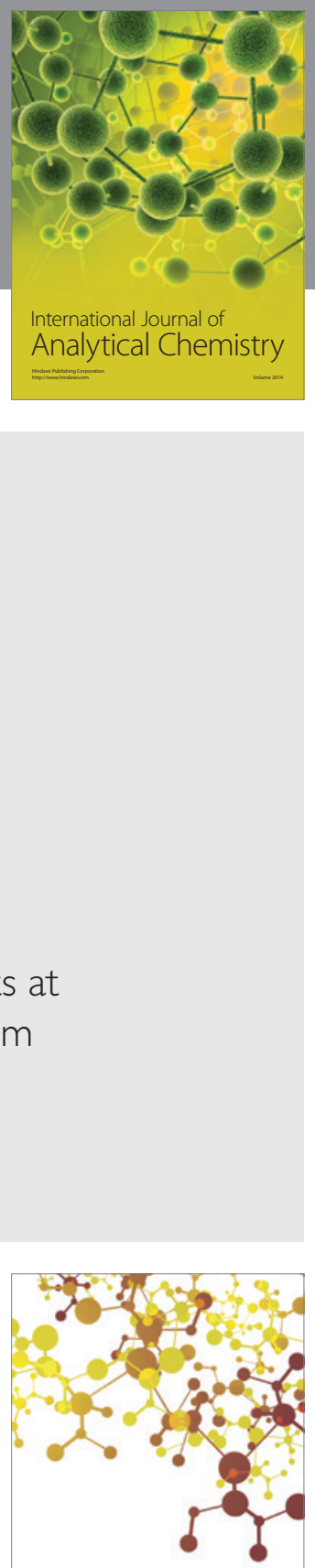

Journal of

Applied Chemistry
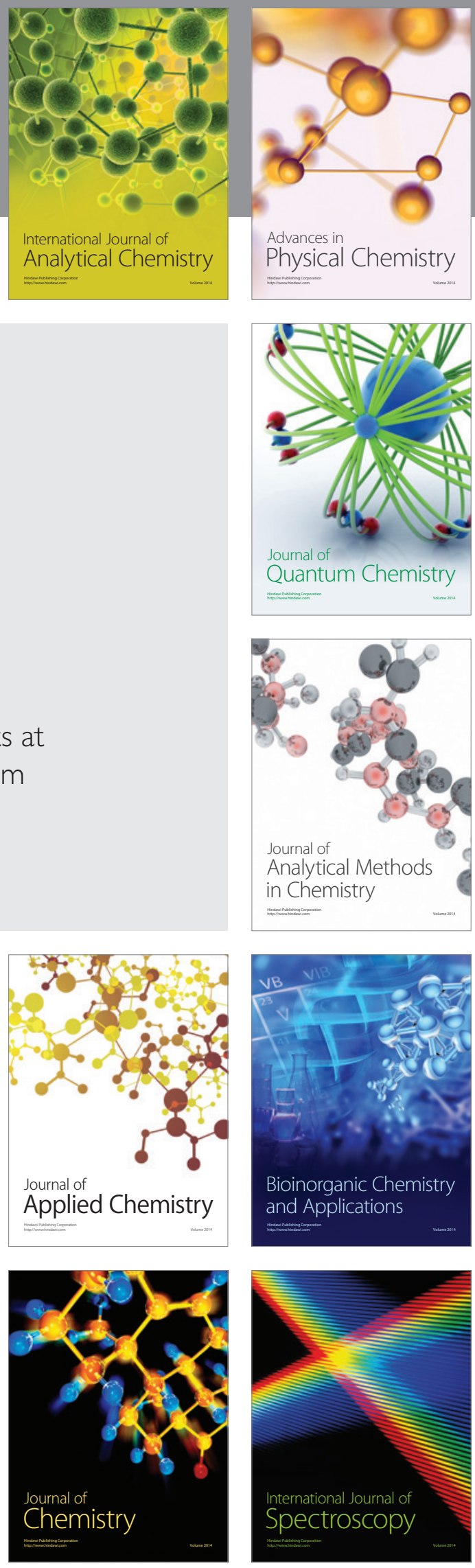